\title{
Influence of different concentrations of 6- benzylaminopurine and thidiazuron on the proliferative activity of apple varieties in in vitro culture
}

\author{
L.V. Tashmatova*, O.V. Matsneva, T.M. Khromova, and V.V. Shakhov
}

Russian Research Institute of Fruit Crop Breeding (VNIISPK), Zhilina, Orel district, Orel region, Russian Federation

\begin{abstract}
An essential role in the process of clonal micropropagation is played by cytokinins, with the help of which apical dominance is removed and the formation of additional shoots and buds is activated. The article presents the study results of microshoots' proliferative activity of apple varieties on media with 6-benzylaminopurine at a concentration of 1.0 $\mathrm{mg} / 1,2.0 \mathrm{mg} / 1$ and thidiazuron at a concentration of $0.1 \mathrm{mg} / 1,0.2 \mathrm{mg} / \mathrm{l}$ and $0.3 \mathrm{mg} / \mathrm{l}$. The objects of research were apple varieties of the VNIISPK selection - Bolotovskoe, Imrus, Veteran, Kandil orlovsky, Girlyanda, Priokskoe. The aim of the research was to study the effect of substances with cytokinin activity on the morphogenesis of apple varieties. As a result of the research, it was revealed that both cytokinins and varietal characteristics influence the multiplication factor. The highest multiplication factor was observed when using 6-BAP. Thidiazuron reduced the proliferation rate. When using 6-BAP, Bolotovskoe, Girlyanda and Priokskoe varieties had the highest multiplication factor among the varieties. When using TDZ - varieties Bolotovskoe and Kandil Orlovsky.
\end{abstract}

\section{Introduction}

In the world industry, the apple tree occupies a significant place among pome crops. Therefore, a topical issue is the establishment of healthy mother plantations of promising varieties. In this regard, there is a need for a sufficient amount of healthy planting material. This problem can be solved with the help of clonal micropropagation, which consists in replicating plants under aseptic conditions on specially selected nutrient media and is used for accelerated propagation of varieties, hybrids, forms and species of plants, as well as for the production of planting material due to a high multiplication factor [1]. The proliferation rate depends on the intensity of adventive buds and shoots formation as a result of apical

* Corresponding author: tashmatova@vniispk.ru 
dominance removal. It is usually carried out using preparations with cytokinin activity. The main physiological effect of cytokinins is the activation of cell division and the regulation of organogenesis, the establishment of stem buds [2]. The cytokinins' group includes both natural compounds (zeatin) and synthetic ones (6-benzylaminopurine, kinetin, 2isopentenyladenine, thidiazuron) [3].

Most often, 6-benzylaminopurine is used in various concentrations (0.5-2.0 mg/l) [4.5]. Thidiazuron is less widespread, but it is also recommended by a number of researchers for the propagation of rootstocks and varieties of fruit crops $[3,6]$. Thidiazuron (TDZ) (Nphenyl-N'-1,2,3-thiadiazole-5-yl-urea) is a herbicide, but at the same time exhibits cytokinin and auxin activity. It causes various morphogenetic reactions of plants, from callus formation to the formation of somatic embryoids [7].

In this regard, the aim of this research was to study the effect of substances with cytokinin activity on the morphogenesis of apple varieties bred by VNIISPK.

\section{Materials and methods}

The objects of research were apple varieties of the VNIISPK selection - Bolotovskoe, Imrus, Veteran, Kandil orlovsky, Girlyanda, Priokskoe. The studies were carried out in accordance with the methodological recommendations by O.V. Matushkina et al. [8], V. G. Trushechkiv, V. A. Vysotsky [9].

Microshoots were cultivated on Quorin-Lepoivre (QL) nutrient medium [10]. 6-BAP at a concentration of 1.0 and $2.0 \mathrm{mg} / \mathrm{l}$ and thidiazuron at a concentration of $0.1,0.2$ and 0.3 $\mathrm{mg} / \mathrm{l}$ were used as growth stimulants. Cytokinins were added to the culture medium prior to autoclaving. The $\mathrm{pH}$ of the nutrient medium was 6.0. The work was carried out in a laminar box under aseptic conditions. Conditions in the culture room: temperature $23-24{ }^{\circ} \mathrm{C}$, illumination 2500-3500 lux created by white LED lamps with a 16-hour photoperiod.

Records were carried out after 4 weeks of cultivation. During four passages, the formed conglomerates of microplants were divided by one at a time and cultured again on the studied nutrient media. Statistical processing of the research results was carried out using the Microsoft Excel computer program (2016) and the recommendations of V. A. Potapov [11].

\section{Results and Discussion}

The main goal of the micropropagation stage is to obtain the maximum number of microshoots from each explant by sequential cultivation of existing microshoots on a fresh nutrient medium. The proliferation degree largely depends on the cytokinin type and its concentration [12].

Studies have shown that an increase in BAP concentration from 1.0 to $2.0 \mathrm{mg}$ led to an increase in the multiplication factor. The concentration of 6-BAP $\left(\mathrm{F}_{\mathrm{f}}>\mathrm{F}_{05}\right)$, varietal characteristics $\left(\mathrm{F}_{\mathrm{f}}>\mathrm{F}_{05}\right)$ and the combined effect of these factors had a significant effect on the multiplication factor.

Often, during the reproduction of apple tree in in vitro culture, a genotypic response to the species and amount of phytohormones is traced, which is caused by the genetic diversity of the Malus genus $[13,14]$. The research results obtained confirm this. Thus, in Bolotovskoe and Imrus varieties, the highest multiplication factor was obtained on a nutrient medium with BAP $1.0 \mathrm{mg} / \mathrm{l}$, which was a control, while in other varieties this indicator increased along with an increase in cytokinin concentration to $2.0 \mathrm{mg} / \mathrm{l}$. This 
increase was especially evident in Veteran and Priokskoe varieties. The multiplication factor from passage to passage increased evenly regardless of the cytokinin concentration, which is reflected in Table 1.

Table 1. Influence of 6-BAP on the proliferation of apple varieties.

\begin{tabular}{|c|c|c|c|c|c|}
\hline $\begin{array}{c}\text { Variety } \\
\text { (factor A) }\end{array}$ & $\begin{array}{c}\text { BAP } \\
\text { concentration, } \\
\mathrm{mg} / \mathrm{l} \\
\text { (factor B) }\end{array}$ & 1passage & 2 passage & 3 passage & $\begin{array}{l}\text { Average } \\
\text { value }\end{array}$ \\
\hline \multirow{2}{*}{ Bolotovskoe } & 1.0 & $1.7 \pm 0.1$ & $2.8 \pm 0.3$ & $4.8 \pm 0.3$ & $3.1 \pm 0.2$ \\
\hline & 2.0 & $1.9 \pm 0.1$ & $2.1 \pm 0.1$ & $2.1 \pm 0.1$ & $2.0 \pm 0.1$ \\
\hline \multirow{2}{*}{ Imrus } & 1.0 & $2.3 \pm 0.3$ & $2.9 \pm 0.3$ & $2.8 \pm 0.3$ & $2.7 \pm 0.3$ \\
\hline & 2.0 & $2.0 \pm 0.1$ & $2.0 \pm 0.1$ & $2.2 \pm 0.1$ & $2.1 \pm 0.1$ \\
\hline \multirow{2}{*}{ Veteran } & 1.0 & $1.2 \pm 0.1$ & $1.6 \pm 0.1$ & $1.7 \pm 0.1$ & $1.5 \pm 0.1$ \\
\hline & 2.0 & $1.5 \pm 0.1$ & $2.0 \pm 0.1$ & $2.3 \pm 0.1$ & $2.1 \pm 0.1$ \\
\hline \multirow{2}{*}{$\begin{array}{c}\text { Kandil' } \\
\text { orlovsky }\end{array}$} & 1.0 & $1.5 \pm 0.1$ & $2.8 \pm 0.3$ & $3.8 \pm 0.3$ & $2.7 \pm 0.3$ \\
\hline & 2.0 & $3.7 \pm 0.4$ & $3.1 \pm 0.2$ & $3.7 \pm 0.3$ & $2.9 \pm 0.2$ \\
\hline \multirow{2}{*}{ Girlyanda } & 1.0 & $2.3 \pm 0.3$ & $3.7 \pm 0.4$ & $3.2 \pm 0.3$ & $3.1 \pm 0.3$ \\
\hline & 2.0 & $5.2 \pm 0.4$ & $4.0 \pm 0.3$ & $4.0 \pm 0.3$ & $4.4 \pm 0.2$ \\
\hline \multirow{2}{*}{ Priokskoe } & 1.0 & $1.1 \pm 0.1$ & $2.9 \pm 0.2$ & $2.2 \pm 0.2$ & $1.5 \pm 0.2$ \\
\hline & 2.0 & $6.2 \pm 0.9$ & $3.8 \pm 0.9$ & $2.7 \pm 0.3$ & $4.3 \pm 0.7$ \\
\hline \multicolumn{6}{|c|}{$\mathrm{LSD}_{05}=1.3 \mathrm{~F}_{\mathrm{f}}>\mathrm{F}_{05}$} \\
\hline
\end{tabular}

However, in varieties Girlyanda and Priokskoye on a medium with BAP $2.0 \mathrm{mg} / \mathrm{l}$, the value of this indicator decreased, which indicates the negative effect of long-term cultivation of these varieties on a nutrient medium with a high BAP content. A lower proliferative activity was noted in varieties Veteran and Priokskoe (1.5) at a BAP concentration of $1.0 \mathrm{mg} / \mathrm{l}$. As the content of BAP in the medium increased, the length of the shoots decreased (Table 2). The results are shown in Table 2.

Table 2. The proportion of apple micro-shoots over $5 \mathrm{~mm}$ under the influence of 6-BAP, $\%$.

\begin{tabular}{|c|c|c|c|c|c|}
\hline \multirow{2}{*}{$\begin{array}{c}\text { Variety } \\
\text { (factor A) }\end{array}$} & $\begin{array}{c}\text { concentration, } \\
\mathrm{mg} / \mathrm{l} \\
\text { (factor B) }\end{array}$ & 1 passage & 2 passage & 3 passage & $\begin{array}{c}\text { Average } \\
\text { value }\end{array}$ \\
\hline \multirow{2}{*}{ Bolotovskoe } & 1.0 & 75.0 & 68.0 & 48.7 & 63.9 \\
\cline { 2 - 6 } & 2.0 & 71.8 & 67.2 & 69.6 & 69.5 \\
\hline \multirow{2}{*}{ Imrus } & 1.0 & 63.4 & 69.6 & 67.2 & 66.9 \\
\cline { 2 - 6 } & 2.0 & 71.4 & 62.3 & 58.4 & 64.1 \\
\hline \multirow{2}{*}{ Veteran } & 1.0 & 87.4 & 83.5 & 80.7 & 83.6 \\
\hline \multirow{2}{*}{$\begin{array}{c}\text { Kandil' } \\
\text { orlovsky }\end{array}$} & 2.0 & 81.7 & 77.7 & 72.4 & 77.3 \\
\hline \multirow{2}{*}{ Girlyanda } & 1.0 & 82.4 & 64.3 & 63.8 & 70.2 \\
\cline { 2 - 6 } & 2.0 & 64.2 & 58.9 & 57.4 & 60.0 \\
\hline \multirow{2}{*}{ Priokskoe } & 1.0 & 72.4 & 63.3 & 73.8 & 69.8 \\
\cline { 2 - 6 } & 2.0 & 54.2 & 68.9 & 77.4 & 66.8 \\
\hline \multicolumn{2}{|c|}{ LSD $05^{2}=5.1 \mathrm{~F} \mathrm{f}>\mathrm{F}_{05}$} & 83.3 & 80.8 & 88.0 \\
\hline
\end{tabular}

This indicator also decreases with each subsequent passage in all varieties. The only exceptions were microshoots of Girlyanda and Priokskoe varieties under the influence of $2.0 \mathrm{mg} / 1 \mathrm{BAP}$. In Veteran variety, $1.0 \mathrm{mg} / 1 \mathrm{BAP}$ reduced the multiplication factor, but 
increased the growth of microshoots. The length of $88.0 \%$ of the shoots was more than $5 \mathrm{~mm}$, while the maximum length was $1.5 \mathrm{~mm}(10 \%)$. Microshoots of Veteran variety also developed well on a medium with BAP $2.0 \mathrm{mg} / \mathrm{l}$.

Thus, varietal specificity is manifested. Mathematical processing showed significant differences between the options. The growth was significantly influenced by the concentration of BAP, varietal characteristics and the combined influence of both factors $\left(\mathrm{F}_{\mathrm{f}}>\mathrm{F}_{05}\right)$.

It is believed that thidiazuron has a higher cytokinin activity compared to 6-BAP and increases proliferative activity [2]; however, in our studies, the addition of this cytokinin to the nutrient medium significantly reduced the multiplication factor in comparison with BAP in all varieties. The most active formation of additional shoots was observed on a medium containing $0.2 \mathrm{mg} / \mathrm{l} \mathrm{TDZ}$. An increase in concentration to $0.3 \mathrm{mg} / \mathrm{l}$ reduced the multiplication factor, which is shown in table 3.

As in the case of the use of BAP, varietal specificity was manifested in microplants. Varieties Bolotovskoe and Kandil Orlovsky $(0.2 \mathrm{mg} / \mathrm{l})$ were distinguished by high proliferative activity. Priokskoe variety had the lowest multiplication factor. Cultivation of this variety on a nutrient medium with $0.3 \mathrm{mg} / \mathrm{TDZ}$ caused the death of plants. This was especially evident in the third passage. In Imrus variety, the formation of vitrified shoots was often observed at all variants of cytokinin concentrations.

Statistical data processing showed a significant effect of thidiazuron concentration on the multiplication factor. The results of studies on thidiazuron effect on the proliferative activity of apple varieties are presented in Table 3.

Table 3. The influence of thidiazuron on the proliferation of apple varieties.

\begin{tabular}{|c|c|c|c|c|c|}
\hline $\begin{array}{c}\text { Variety } \\
\text { (factor A) }\end{array}$ & $\begin{array}{c}\text { TDZ } \\
\text { concentration, } \\
\mathrm{mg} / \mathrm{l} \\
\text { (factor B) }\end{array}$ & 1passage & 2 passage & 3 passage & $\begin{array}{c}\text { Average } \\
\text { value }\end{array}$ \\
\hline \multirow{3}{*}{ Bolotovskoe } & 0.1 & $2.4 \pm 0.3$ & $2.9 \pm 0.5$ & $2.1 \pm 0.3$ & $2.5 \pm 0.4$ \\
\cline { 2 - 6 } & 0.2 & $2.9 \pm 0.6$ & $3.9 \pm 0.4$ & $2.4 \pm 0.3$ & $3.1 \pm 0.3$ \\
\cline { 2 - 6 } Imrus & 0.3 & $1.7 \pm 0.1$ & $1.3 \pm 0.1$ & $1.4 \pm 0.1$ & $1.5 \pm 0.1$ \\
\cline { 2 - 6 } & 0.1 & $1.2 \pm 0.1$ & $1.5 \pm 0.1$ & $2.9 \pm 0.1$ & $1.9 \pm 0.1$ \\
\cline { 2 - 6 } & 0.2 & $2.8 \pm 0.3$ & $2.3 \pm 0.2$ & $2.3 \pm 0.3$ & $2.6 \pm 0.3$ \\
\hline \multirow{3}{*}{ Veteran } & 0.3 & $2.4 \pm 0.3$ & $2.1 \pm 0.3$ & $2.1 \pm 0.2$ & $2.2 \pm 0.3$ \\
\cline { 2 - 6 } & 0.1 & $2.8 \pm 0.4$ & $2.1 \pm 0.1$ & $1.6 \pm 0.1$ & $2.2 \pm 0.1$ \\
\cline { 2 - 6 } & 0.2 & $2.4 \pm 0.2$ & $1.8 \pm 0.1$ & $3.1 \pm 0.4$ & $2.4 \pm 0.3$ \\
\hline \multirow{3}{*}{ Kandil' } & 0.3 & $2.0 \pm 0.1$ & $1.6 \pm 0.1$ & $1.5 \pm 0.1$ & $1.7 \pm 0.1$ \\
\cline { 2 - 6 } & 0.1 & $1.8 \pm 0.2$ & $2.0 \pm 0.2$ & $1.1 \pm 0.1$ & $1.6 \pm 0.2$ \\
\cline { 2 - 6 } & 0.2 & $3.3 \pm 0.3$ & $3.2 \pm 0.4$ & $3.0 \pm 0.3$ & $3.2 \pm 0.3$ \\
\hline \multirow{3}{*}{ Girlyanda } & 0.3 & $2.1 \pm 0.2$ & $1.3 \pm 0.1$ & $1.7 \pm 0.1$ & $1.7 \pm 0.1$ \\
\cline { 2 - 6 } & 0.1 & $1.6 \pm 0.2$ & $1.8 \pm 0.2$ & $1.5 \pm 0.1$ & $1.6 \pm 0.1$ \\
\cline { 2 - 6 } & 0.2 & $2.6 \pm 0.2$ & $3.3 \pm 0.4$ & $2.2 \pm 0.2$ & $2.7 \pm 0.3$ \\
\hline \multirow{3}{*}{ Priokskoe } & 0.3 & $2.3 \pm 0.2$ & $1.6 \pm 0.1$ & $1.6 \pm 0.2$ & $1.8 \pm 0.2$ \\
\cline { 2 - 6 } & 0.1 & $1.4 \pm 0.1$ & $1.6 \pm 0.1$ & $1.3 \pm 0.1$ & $1.4 \pm 0.1$ \\
\cline { 2 - 6 } & 0.2 & $1.7 \pm 0.2$ & $2.3 \pm 0.4$ & $2.2 \pm 0.2$ & $2.1 \pm 0.3$ \\
\hline & 0.3 & $2.0 \pm 0.2$ & $1.6 \pm 0.1$ & $1.1 \pm 0.1$ & $1.6 \pm 0.1$ \\
\hline
\end{tabular}

The varietal characteristics, TDZ concentration, and the combined effect of two factors significantly influenced the length of microshoots. A large number of shoots over $5 \mathrm{~mm}$ was obtained on a medium containing $0.1 \mathrm{mg} / \mathrm{l} \mathrm{TDZ}$ in varieties Imrus (78.5\%), Kandil 
Orlovsky (92.0\%), Girlyanda (78.6\%) and Priokskoe (91.9\%), Veteran - on medium with $0.2 \mathrm{mg} / \mathrm{l}$, with an increase in concentration to $0.3 \mathrm{mg} / \mathrm{l}$ the growth of shoots stopped abruptly. The TDZ concentration of $0.3 \mathrm{mg} / 1$ stimulated the formation of a shoot of more than $5 \mathrm{~mm}$ in Botovskoe variety (72.3\%). The maximum shoot length amounted to no more than $18 \mathrm{~mm}$ and $(16 \%)$. Most of the shoots were $10-11 \mathrm{~mm}$ long. In shoots of all varieties except Imrus, the leaves were well developed and had a dark green color.

In Bolotovskoe variety, the maximum proportion of shoots of more than $5 \mathrm{~mm}$ was obtained on a medium containing $0.3 \mathrm{mg} / 1 \mathrm{TDZ}$ (72.3\%). At TDZ concentrations of $0.1 \mathrm{mg} / 1$ and 0.2 , microshoots developed uniformly, while the proportion of such shoots increased at $0.3 \mathrm{mg} / \mathrm{l}$. In Imrus variety, the highest percentage of shoots was obtained on a medium with $0.1 \mathrm{mg} / 1 \mathrm{TDZ}$ (78.5). However, over the course of three passages, this indicator decreased the same as at a concentration of $0.2 \mathrm{mg} / \mathrm{l}$. In Veteran variety, the maximum number of shoots of more than $5 \mathrm{~mm}$ was obtained under the influence of $0.2 \mathrm{mg} / \mathrm{lDZ}$ (78.2\%) and this indicator also decreased from the first to the third passage. In Kandil orlovsky variety, the percentage of shoots of a given length increased steadily from the first passage to the third. In varieties Girlyanda and Priokskoye, the value of this development indicator decreased at TDZ concentration of $0.2 \mathrm{mg} / \mathrm{l}$, and then increased again with an increase in concentration to $0.3 \mathrm{mg} / \mathrm{l}$, but was still lower than at $0.1 \mathrm{mg} / \mathrm{l}$. The results obtained are shown in Table 4.

Table4. The share of apple tree micro-shoots over than $5 \mathrm{~mm}$ under the influence of thidiazuron, $\%$.

\begin{tabular}{|c|c|c|c|c|c|}
\hline $\begin{array}{c}\text { Variety } \\
\text { (factor A) }\end{array}$ & $\begin{array}{c}\mathrm{TDZ} \\
\text { concentration, } \\
\mathrm{mg} / \mathrm{l} \\
\text { (factor B) }\end{array}$ & 1passage & 2 passage & 3 passage & $\begin{array}{l}\text { Average } \\
\text { value }\end{array}$ \\
\hline \multirow{3}{*}{ Bolotovskoe } & 0.1 & 55.0 & 55.0 & 54.5 & 54.8 \\
\hline & 0.2 & 56.7 & 67.0 & 52.6 & 52.0 \\
\hline & 0.3 & 58.8 & 79.0 & 81.5 & 72.3 \\
\hline \multirow{3}{*}{ Imrus } & 0.1 & 88.3 & 77.0 & 70.2 & 78.5 \\
\hline & 0.2 & 80.6 & 75.0 & 54.7 & 70.1 \\
\hline & 0.3 & 65.2 & 64.0 & 64.0 & 64.4 \\
\hline \multirow{3}{*}{ Veteran } & 0.1 & 64.8 & 62.0 & 58.0 & 61.6 \\
\hline & 0.2 & 81.6 & 77.0 & 76.0 & 78.2 \\
\hline & 0.3 & 30.0 & 19.0 & 43.3 & 30.8 \\
\hline \multirow{3}{*}{$\begin{array}{c}\text { Kandil' } \\
\text { orlovsky }\end{array}$} & 0.1 & 76.0 & 100 & 100 & 92.0 \\
\hline & 0.2 & 48.0 & 47.0 & 66.0 & 57.0 \\
\hline & 0.3 & 39.0 & 76.9 & 83.0 & 66.3 \\
\hline \multirow{3}{*}{ Girlyanda } & 0.1 & 72.4 & 73.4 & 90.0 & 78.6 \\
\hline & 0.2 & 35.0 & 60.7 & 72.0 & 56.0 \\
\hline & 0.3 & 58.8 & 85.7 & 67.4 & 70.6 \\
\hline \multirow{3}{*}{ Priokskoe } & 0.1 & 83.8 & 100 & 92.0 & 91.9 \\
\hline & 0.2 & 85.0 & 80.7 & 82.0 & 82.6 \\
\hline & 0.3 & 42.6 & 58.0 & 94.7 & 65.1 \\
\hline \multicolumn{5}{|c|}{$\mathrm{LSD}_{05}=16.5 \mathrm{~F}_{\mathrm{f}}>\mathrm{F}_{05}$} & 67.9 \\
\hline
\end{tabular}

\section{Conclusions}

When cultivating apple varieties in vitro on nutrient media with BAP and thidiazuron of various concentrations, the effect of the genotype and cytokinins on their proliferative 
activity and the intensity of shoot formation was observed, which can later be used both at the reproduction stage and at the stage of elongation. Varieties Girlyanda and Priokskoye differed in the highest multiplication factor when using 6-BAP and amounted to 4.4 and 4.3 units/expl. In Bolotovskoe variety, the degree of proliferation was the same on media with both stimulants and amounted to 3.1 pcs. /expl. For the rest of the varieties, the multiplication factor ranged from 1.5 to $2.9 \mathrm{pcs}$. /expl. when cultivated on a medium containing BAP and from 1.4 to $2.7 \mathrm{pcs}$. /expl. on a medium with thidiazuron. Thus, the multiplication factor was low. The share of microshoots of more than $5 \mathrm{~mm}$ was on average equal in both stimulant variants and amounted to 70.3 and $67.9 \%$. Thidiazuron is not suitable for the cultivation of Priokskoe variety microshoots.

\section{References}

1. Yu. Kovalchuk, B.Zh. Kabylbekova, N.I. Chukanova, T.T. Turdiyev, S.N. Frolov, Vestnik of the Nizhny Novgorod State Agricultural Academy 3(27), 5-12 (2020)

2. V.S. Sheveluha, E.A. Kalashnikova, S.V. Degtyarev, E.Z. Kochieva, M.I. Prokofev, N.N. Novikov, V.M. Kovalev \&

3. D.V. Kalashnikov, Agricultural Biotechnology 416 (1998)

4. O.V. Matushkina, I.N. Pronina, Achievements of science and technology of the Agroindustrial complex 8, 34-35 (2010)

5. S. J. Isroilova, International Scientific Journal Theoretical \& Applied Science 05(73), 531-535 (2019) doi.org/10.15863/TAS.2019.05.73.81

6. E.N. Raeva-Bogoslovskaya, O.I. Molkanova, V.A. Kryuchkova, "International Scientific and Practical Conference "Fundamental and Applied Research in Biology and Agriculture: Current Issues, Achievements and Innovations", FARBA 2021" (2021)

7. I.A. Byadovsky, Pomiculture and small fruits culture in Russia 37(1), 52-56 (2013)

8. L.S. Nesmelova, T.V., Zheleznichenko, M.S Voronkova, D.S. Muraseva, Effect of thidiazuron on morphogenesis of Picea pungens in vitro. Problems of botany of Southern Siberia and Mongolia, XVII International Scientific and practical conference, 17, 217-220 (2018)

9. O.V. Matushkina, I.N. Pronina, Technology of clonal micropropagation of apple and pear trees (methodological recommendations), 32 (2008)

10. V.G. Trushechkin, V.A. Vysotsky, O.A. Leontiev-Orlov, Methodological guidelines for clonal micro-reproduction of rootstocks and apple varieties, 19 (1985)

11. M. Quorin, P. Lepoivre, Acta Hortic 78(4), 437-442 (1977)

12. V.A. Potapov, Methods of processing experimental data in fruit growing (Recommendations), 144 (1997)

13. L.L Buntsevich, A.T Kiyan, E.N Besedina, M.A Kostyuk, Pomiculture and small fruits culture in Russia 37(1), 46-51 (2013)

14. J. Dobránszk, J.A. Teixeira da Silva Biotechnology Advances 28, 4, 462-488 (2010)

15. L.V. Tashmatova, O.V. Matsneva, T.M. Khromova, V.V. Shakhov, E3S Web of Conferences, FARBA 2021 (2021) 